\title{
Five Years of Reef Check Monitoring Data for Tioman, Perhentian and Redang Island
}

\author{
Julian Hyde*, Chen Sue Yee \& Alvin Chelliah
}

Reef Check Malaysia, Box \#606, 5.19 - 5.22 Wisma Central, Jalan Ampang, 50450 Kuala Lumpur, Malaysia

*julian@reefcheck.org.my (corresponding author)

\begin{abstract}
The Reef Check survey methodology was designed for use by non-scientists to assess the health of coral reefs. The methodology focuses on the abundance of particular coral reef organisms that best reflect the condition of the ecosystem and that are easily recognisable to non-scientists. Selection of these "indicator" organisms was based on their economic and ecological value, their sensitivity to human impacts and ease of identification, allowing large numbers of non-scientists to participate in surveys. Indicators include a broad spectrum of fish, invertebrates and substrate categories that reflect human activities such as fishing, collection or pollution. The first global survey programme in 1997 provided scientific confirmation that coral reefs were facing a major crisis on a global scale. Since 2007, Reef Check Malaysia has conducted an annual Reef Check survey programme of Malaysia's coral reefs. The paper presents an analysis of five years of data (2007-2011) collected from over 100 survey sites in both Peninsular and East Malaysia. Changing populations of fish and variations in live coral cover highlight local impacts on coral reefs, providing valuable information for managers and scientists. Data can be used to manage local threats to coral reefs, and contributes to building coral reef resilience.
\end{abstract}

(Keywords: Reef Check, coral reefs, survey, Tioman, Perhentian, Redang)

\section{INTRODUCTION}

Coral reefs are the most diverse marine ecosystems on earth [15]. They are an important ecological and economic resource in many countries around the world, providing a range of valuable ecosystem services to millions of people [9][15]. More than 39\% of the world population lives within $100 \mathrm{~km}$ of the coast [5] and many people in these areas depend largely on coral reefs for food, coastal protection, cultural items, and tourism income; approximately 30 million of the poorest people depend completely on coral reefs for food [11]. In Southeast Asia more than 138 million people live on the coast within $30 \mathrm{~km}$ of a coral reef [4] which is more than in all of the other coral reef regions combined.

The coastline in Malaysia is estimated to have about $4,006 \mathrm{~km}^{2}$ of coral reefs [1]. Little reef development occurs along the heavily sedimented west coast of Peninsular (or West) Malaysia, but the east coast of Peninsular Malaysia has some fringing reefs along the coast and many continental reefs around its offshore islands[16][3]. East Malaysia consists of the Malaysian states of Sabah and Sarawak, and makes up the northern one third of the island of Borneo. Due to high sedimentation and land-based pollution, reef development around Sarawak is limited [3]. However, Sabah has reefs along nearly its entire coastline and surrounding most of its islands [10].

A total of 346 species of coral have been recorded in Malaysia, and many of Peninsular Malaysia's coral reefs are protected within Marine Parks and Reserves under the Fisheries Act 1985 [16]. In East Malaysia, the coral reefs in northeast and southwest Sarawak are protected by the Department of Fisheries Sarawak, and many of the coral reefs in Sabah are protected by Sabah Parks. In general, studies show nearly one third of the reefs in Malaysia have between 25 to 50\% live coral cover, very few reefs with more than $75 \%$ live coral cover [14], and over $85 \%$ of the reefs are threatened by human activities [3].

Reef Check surveys are based on the philosophy of "Indicator Species". These are marine organisms that are widely distributed on coral reefs, easy for non-scientists to identify and provide information about the health of a coral reef. Using a standardised methodology, data from 
surveys in different sites can be compared on a national, regional or international basis (see www.reefcheck.org for more details).

The Reef Check monitoring methodology allows scientists and managers to track changes to coral reefs over time. By surveying reefs on a regular basis, deleterious changes can be highlighted early, before they become problems. This gives managers the opportunity to intervene, carry out additional detailed studies and/or initiate management actions to try to reverse the change before permanent damage is done to the reef.

Although an effort was made to ensure that the Reef Check monitoring methodology is compatible with others methods used to monitor substrate cover, fish abundance and invertebrate abundance particularly those used by Global Coral Reef Monitoring Network (GCRMN), it represents a major step forward in the development of community-based monitoring methods and differs in major ways from any other previous methods [6].

Reef Check methods differ from others because they: 1) require minimal training time (typically a few hours as compared with the several days required to train other methods), 2) are much faster than most methods (half day per reef), 3) are designed for non-scientists who are experienced divers with at least a high school education so the pool of potential data collectors is huge, 4) can easily be carried out in shallow water without scuba, because they depend on counting (no measuring), 5) are holistic and include algae, fish and invertebrates; 6) include organisms selected based on market value and ecological role, 7) include an assessment of fishing and other human activities; 8) produce a relatively small amount of accurate, extremely meaningful and statistically comparable data; 9) produce data that are directly relevant to reef management; 10) produce data that are nationally, regionally and globally comparable; and 11) include separate packages for different biogeographic regions that allow intraregional comparisons.

Reef Check data is now widely accepted and published in scientific journals [2] and the methodology is commonly used by scientists and non-scientists [6][12].

\section{MATERIALS AND METHODS}

Reef Check surveys were conducted along a fixed depth or two depth contours ( $3 \mathrm{~m}$ to $6 \mathrm{~m}$ and $6 \mathrm{~m}$ to $12 \mathrm{~m}$ depth) when possible. A $100 \mathrm{~m}$ transect line was deployed and four $20 \mathrm{~m}$ sections were surveyed, each section separated by $5 \mathrm{~m}$, which provided four replicates per transect for statistical analysis.

Four types of data were collected, including the abundance of fish commonly targeted by fishermen and aquarium collectors, the abundance of invertebrates commonly targeted as food species or collected as curios, percentage cover of substrate category and an impact survey involving the assessment of damage to coral from bleaching, anchoring, destructive fishing, corallivores such as Drupella snails or crown-of-thorns starfish, and trash. Data for coral damage was collected based on a point scale where no damage received 0 points and minor damage 1 point, average damage 2 points and severe damage 3 points.

\section{Fish Belt Transect}

The fish belt transect was the first survey completed during each dive because fish can easily be disturbed by divers. A lag period of 15 minutes before starting the fish visual survey was allocated after transect line deployment. This waiting period was necessary to allow the fishes to resume normal behaviour after being disturbed by the diver deploying the transect line [8]

Divers assigned to count fish swam slowly along the transect line counting the indicator fish seen within $2.5 \mathrm{~m}$ on either side of the transect line and up to $5 \mathrm{~m}$ above the transect line. At every $5 \mathrm{~m}$ along the transect line, divers stop and wait for one minute before proceeding to the next $5 \mathrm{~m}$ stop point. The stop is necessary for indicator fish to come out of hiding [8]. The indicator fish were butterflyfish (Chaetodontidae), sweetlips (Haemulidae), snapper (Lutjanidae), barramundi cod (Cromileptes altivelis), humphead wrasse (Cheilinus undulates), bumphead parrotfish (Bolbometopon muricatum), parrotfish (Scaridae), moray eel (Muraenidae), and grouper (Serranidae).

Fish were counted while the diver was swimming and while stopped along the entire length of each $20 \mathrm{~m}$ transect. This was a combined timed and area restricted survey: four segments $\times 20 \mathrm{~m}$ long $\times 5 \mathrm{~m}$ wide $=400 \mathrm{~m}^{2}$, with three $5 \mathrm{~m}$ gaps where no data were/are collected. At each depth contour, there were/are 16 "stop-and-count" points, and the goal is to complete the entire $400 \mathrm{~m}^{2}$ belt transect in one hour [8].

\section{Invertebrate Belt Transect}

Once the fish belt transect had been completed, divers assigned to count invertebrate carried out the belt 
transect survey for invertebrates using the same belt transect that was used for the fish survey. The total surveyed area was $20 \mathrm{~m} \times 5 \mathrm{~m}=100 \mathrm{~m}^{2}$ for each segment and $400 \mathrm{~m}^{2}$ for one complete transect of 4 segments. Although the invertebrate survey was similar to the fish survey, the diver did not need to stop every $5 \mathrm{~m}$, instead each diver swam slowly along the transect counting the indicator invertebrates [8]. The indicator invertebrates were banded coral shrimp (Stenopus hispidus), Diadema urchin (Diadema spp.), pencil urchin (Eucidaris tribuloides), collector urchin (Tripneustes spp.), sea cucumber (Thelenota ananas, Stichopus chloronotus, Holothuria edulis), crown of thorns (Acanthaster planci), triton shell (Charonia spp.), lobster (Decapoda), and giant clam (Tridacna spp.).

\section{Line Transect}

When the invertebrate belt transect was almost completed, divers assigned to record substrate began the line transect. Data on substrate was collected using the Point Intercept method, which involved recording the code of the substrate type that lied directly below the transect line at $0.5 \mathrm{~m}$ intervals i.e. at: $0.0 \mathrm{~m}, 0.5 \mathrm{~m}$, $1.0 \mathrm{~m}, 1.5 \mathrm{~m}$ etc. up to $19.5 \mathrm{~m}$ (40 data points per 20 $\mathrm{m}$ transect segment) [8]. The substrate were hard coral (HC), soft coral (SC), nutrient indicator algae (NIA), other (OT), sponge (SP), rock (RC), recently killed coral (RKC), rubble (RB), silt (SI), and sand (SD).
All raw data were entered into Reef Check Excel spreadsheets (data forms) which had built-in macros to calculate the mean, standard deviation, standard error and totals for parameters of interest.

\section{RESULTS AND DISCUSSION}

\section{Fish}

Indicator fish populations varied widely and no apparent trend could be made out from the data collected, (Figures 1, 2 and 3). However, all islands had a common feature; the populations of prized fish such as Baramundi Cod and Humphead Wrasse appeared to be almost zero over the past five years and the population of moray eel was always less than one per $500 \mathrm{~m}^{3}$. These findings were predictable as their absence or low numbers were common in many studies. According to Hodgson [7], the absence of Baramundi Cod and Humphead Wrasse implies that they were being heavily exploited. These fish were intensely fished in the past and their populations are still recovering. Tighter enforcement of Marine Park regulations may aid the recovery of these fish population and on-going monitoring will help to track recovery of populations. The near-absence of moray eel on the other hand was probably due to their nocturnal habits, hiding in crevices, holes, and under rocks or coral during the day, and coming out at night

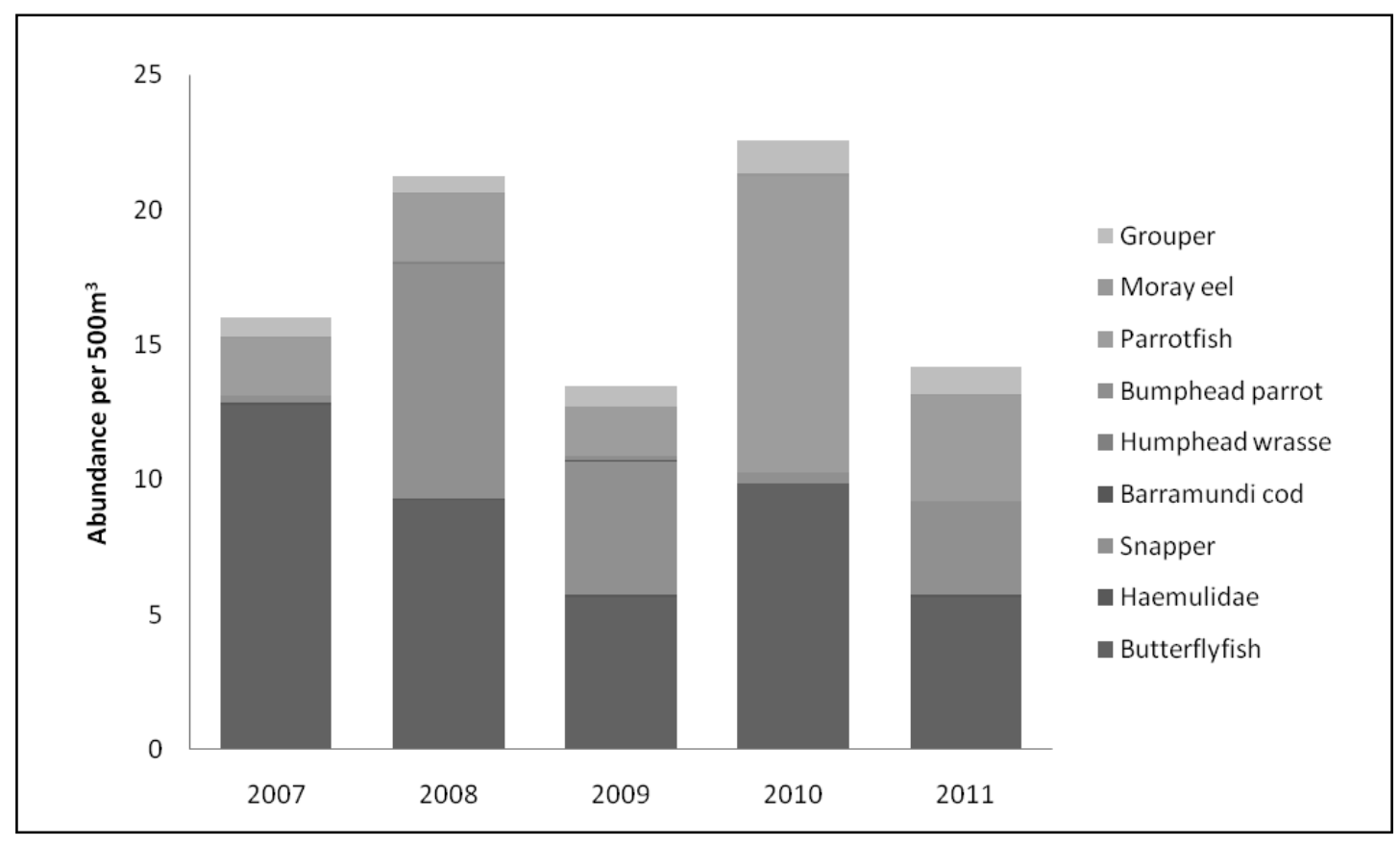

Figure 1. Fish Abundance for Tioman Island from 2007 to 2011 


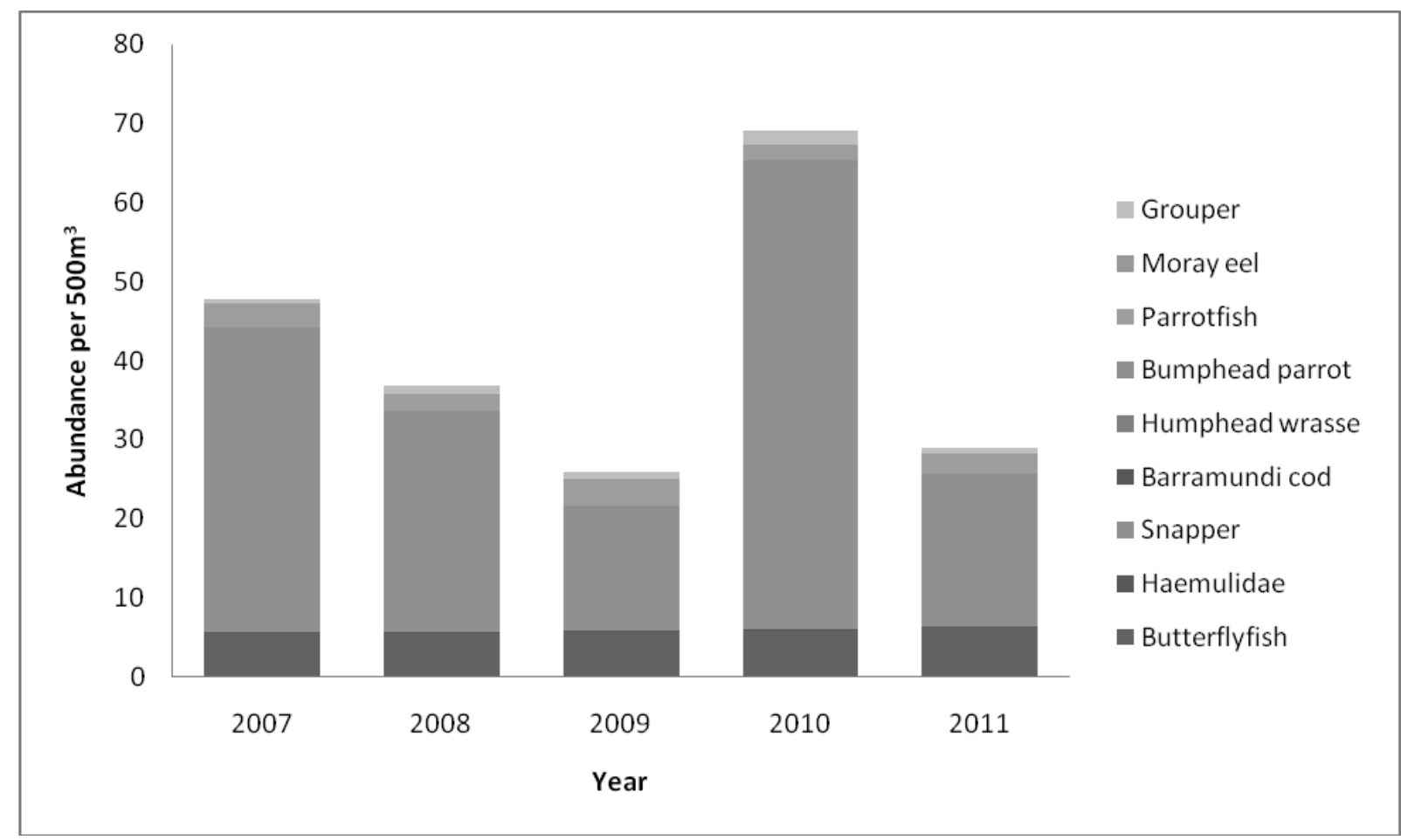

Figure 2. Fish Abundance for Perhentian Island from 2007 to 2011

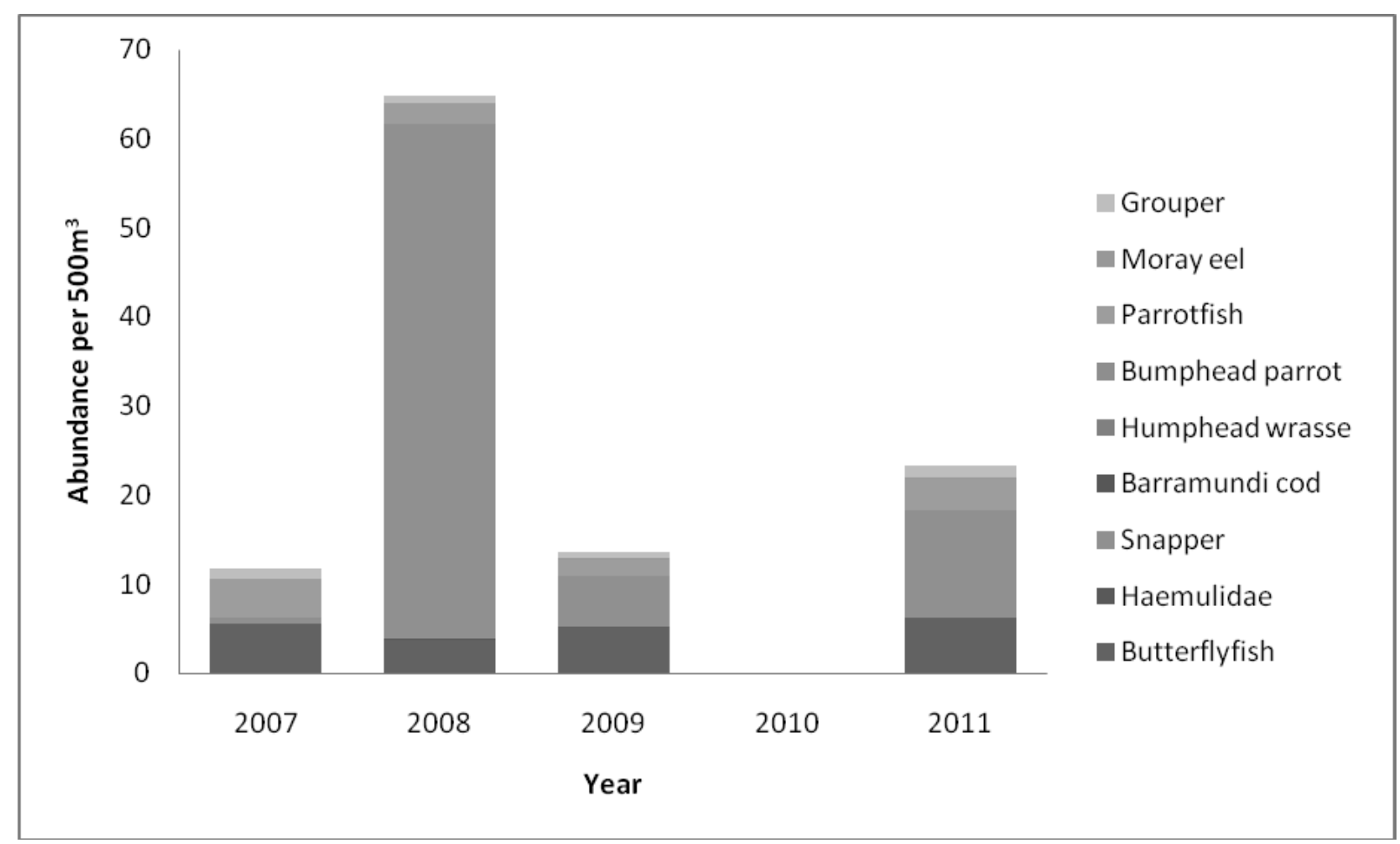

Figure 3. Fish Abundance for Redang Island from 2007 to 2011 
[13]. The presence of butterfly fish in all survey sites is a good indication that fishing for the aquarium trade is not a problem in these islands as this fish is commonly targeted for this trade and is usually missing on reefs fished for the aquarium trade [7].

\section{Invertebrates}

The populations of targeted invertebrate showed wide variations and the data displayed no apparent trend (Figures 4, 5 and 6). Banded coral shrimp, pencil urchin, collector urchin, triton shell and lobster were almost completely absent from surveys at all islands for the past five years. According to Hodgson [7], these four indicator species are highly prized by the curio trade. Significant collecting in the past is the most likely reason for their absence.
Numbers of Diadema urchin in Tioman were the highest of all islands surveyed, followed by Perhentian. In a balanced reef ecosystem, the numbers of Diadema urchins, in combination with herbivorous fish, keep algal growth in check [7]. However, these urchins can reproduce rapidly in conditions in which their main food source (microalgae and macroalgae, which proliferate in nutrient rich water) is abundant. Thus, high or increasing numbers of Diadema could indicate above normal levels of nutrient, causing algae to grow. In very high numbers, Diadema can have two negative impacts. First, if algae is scarce, their feeding preference can change to coral tissue, and secondly large numbers actively grazing can cause bioerosion rates that exceed the rate of coral growth. Controlling nutrient pollution can contribute to reducing this problem, as can healthy populations of herbivores.

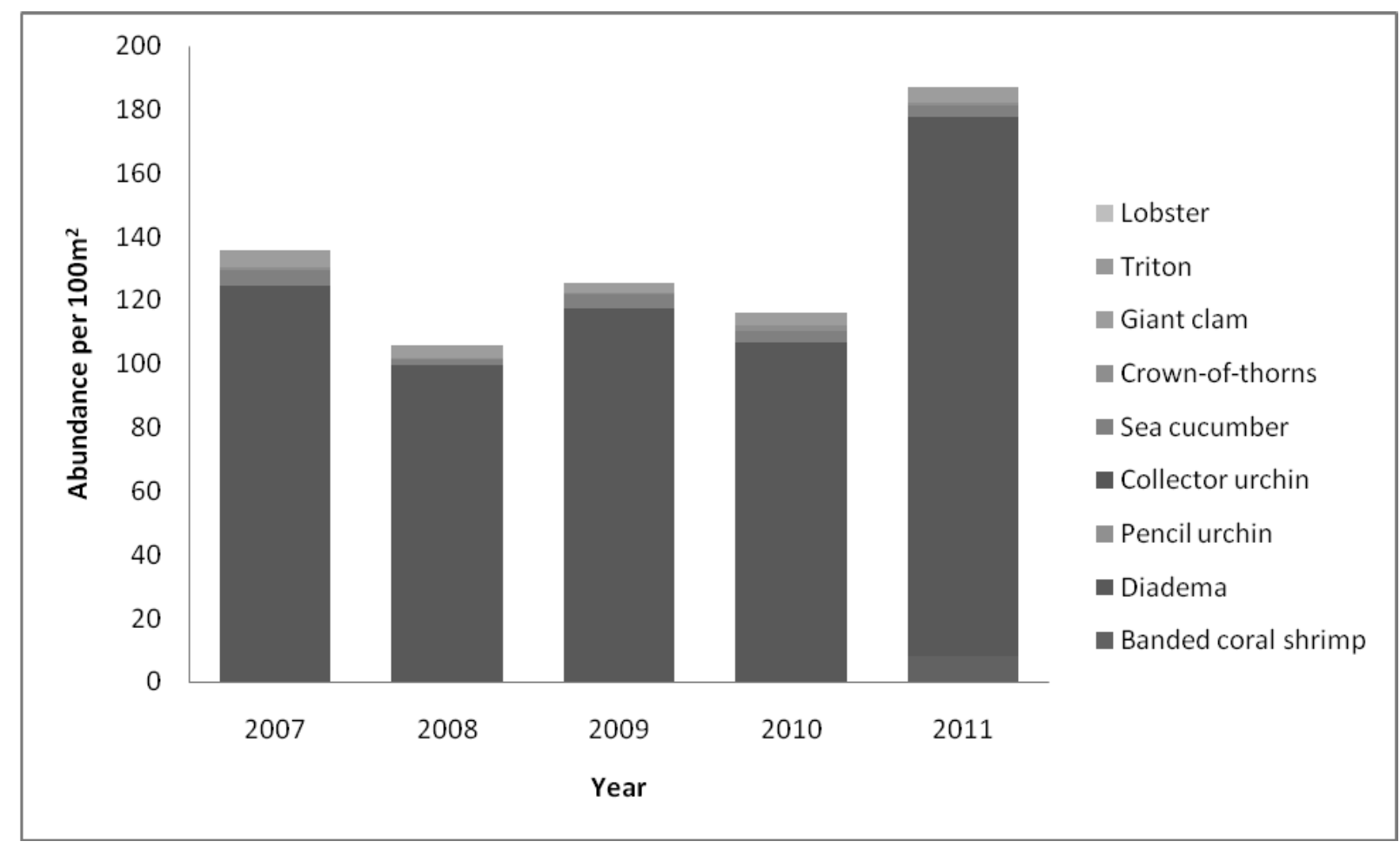

Figure 4. Invertebrate Abundance for Tioman Island from 2007 to 2011 


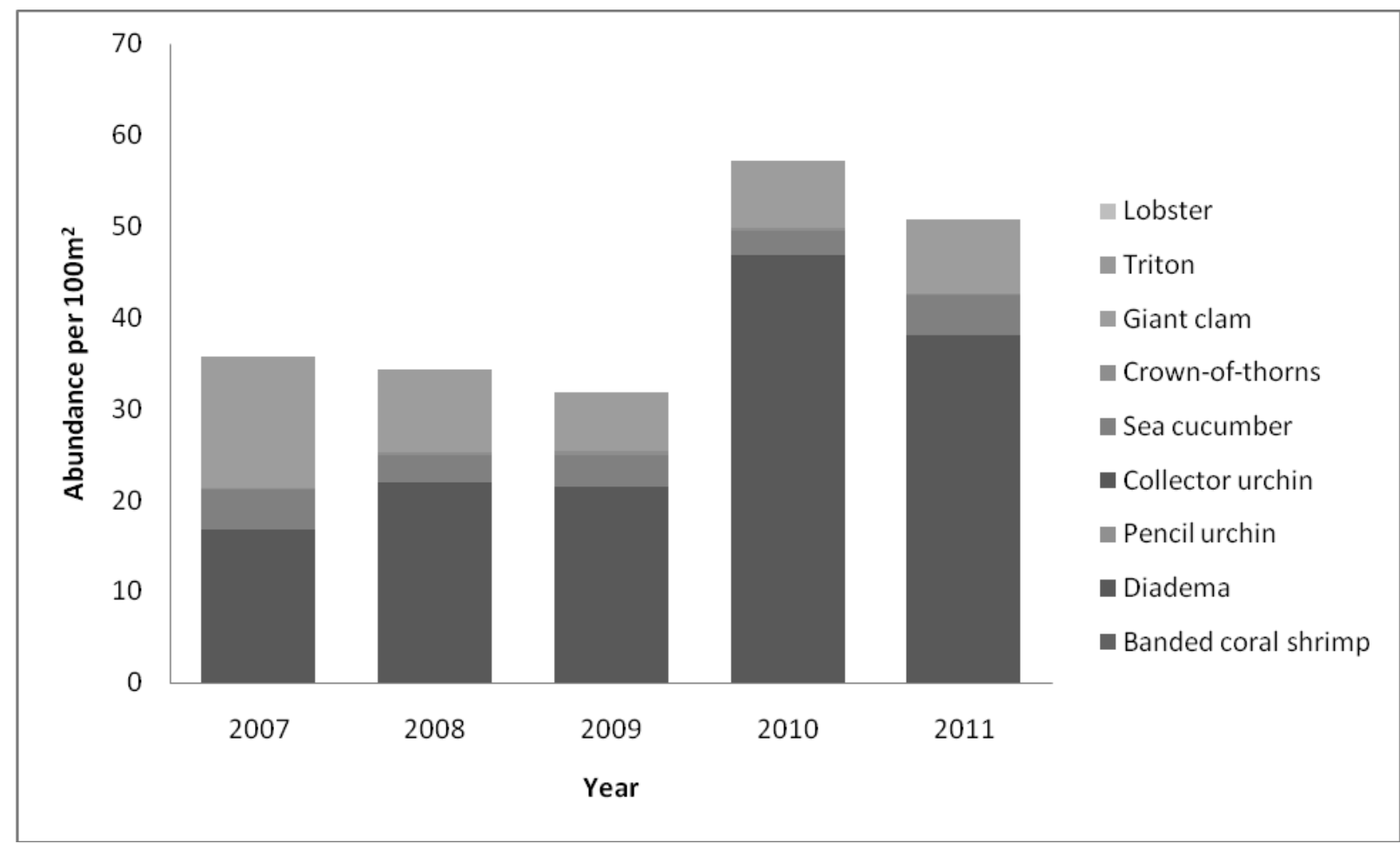

Figure 5. Invertebrate Abundance for Perhentian Island from 2007 to 2011

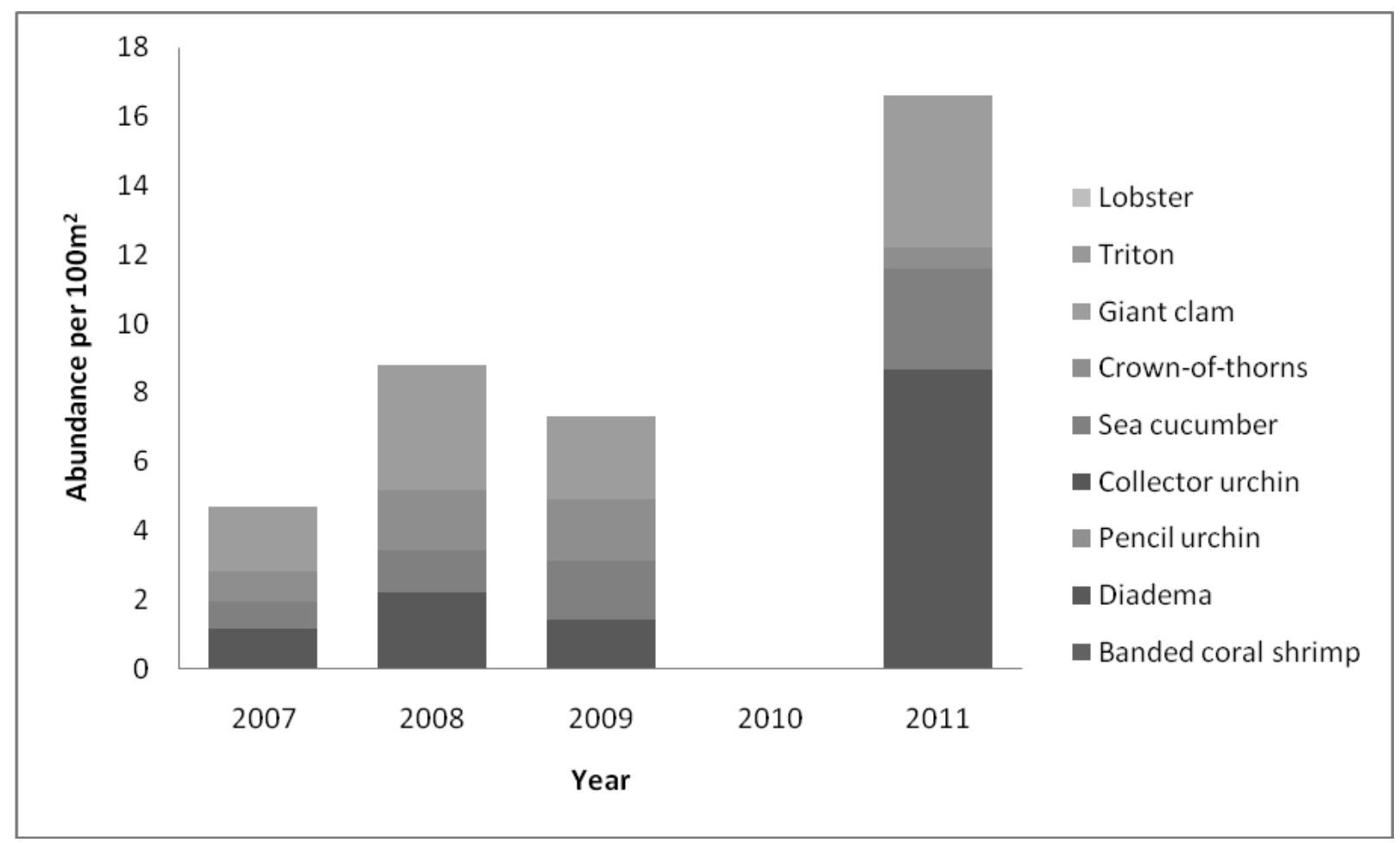

Figure 6. Invertebrate Abundance for Redang Island from 2007 to 2011 


\section{Substrate}

The average live coral (hard + soft) cover around Tioman island (Figure 7) has not changed much in the past five years with an average of $54.41 \%$ live coral cover per $20 \mathrm{~m}$ surveyed. Both the proportion of RKC $1.94 \%$ and
NIA 3.41\% have remained relatively low, reflecting relatively low degree of recent damage to reefs due to natural or human factors and low levels of nutrient in the waters around the islands respectively.

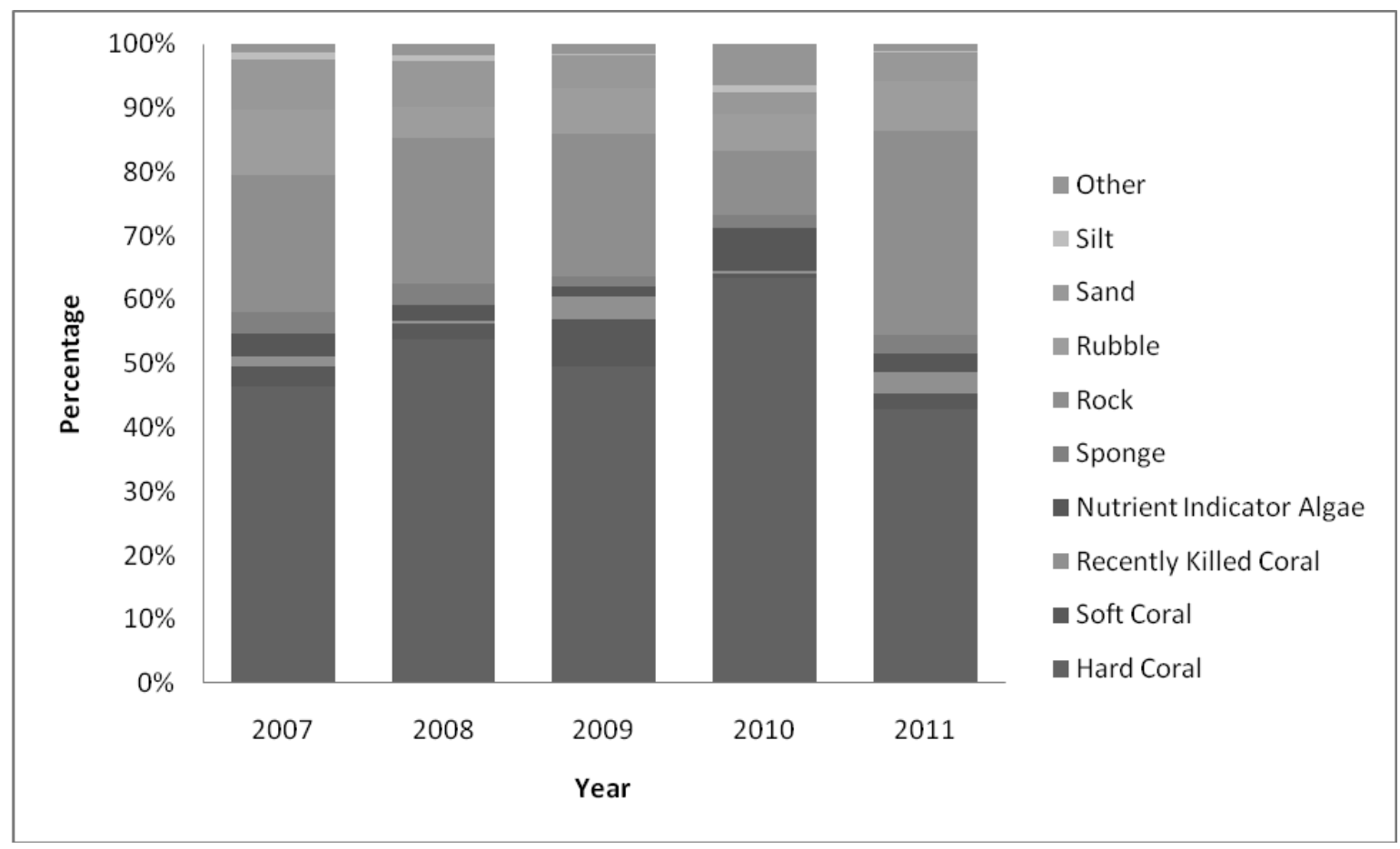

Figure 7. Substrates cover for Tioman Island from 2007 to 2011

The average live coral cover (41.47\% per $20 \mathrm{~m}$ surveyed) around the Perhentian islands has been decreasing since 2009 (Figure 8). In 2009 the average live coral cover was $20.09 \%$ and in 2011 it was $14.54 \%$ per $20 \mathrm{~m}$ of reef surveyed. The level of NIA has maintained at high level (average of 10.6\%), indicating steady high levels of nutrient in the waters around the islands. The most likely source of this is the islands' resorts, most of which have limited sewage treatment facilities. In 2010 there was a wide scale bleaching event and this also could have further contributed to the decrease in live coral cover. The proportion of RC is also maintained at high level (average of 36.7\%), a significant proportion of which is dead coral.

The average live coral (hard + soft) cover (45.75\% per $20 \mathrm{~m}$ ) around Redang Island has not changed much in the past five years (Figure 9). The proportion of RKC has remained low (1.08\%), reflecting a relatively low degree of recent damage to reefs due to natural or human factors. In the past five years, the level of NIA has decreased from $12.66 \%$ to $3.50 \%$, indicating lower levels of nutrient in the waters around the islands.

\section{CONCLUSION}

The low abundances of indicator fish in Tioman, Perhentian and Redang suggest that high value food fish have been overfished in the past and it is likely that only strict enforcement of regulations will allow populations to recover. The total absences of certain invertebrates such as the triton shell and pencil urchin on the other hand indicate that possibly there is little reproduction occurring naturally. Introducing 


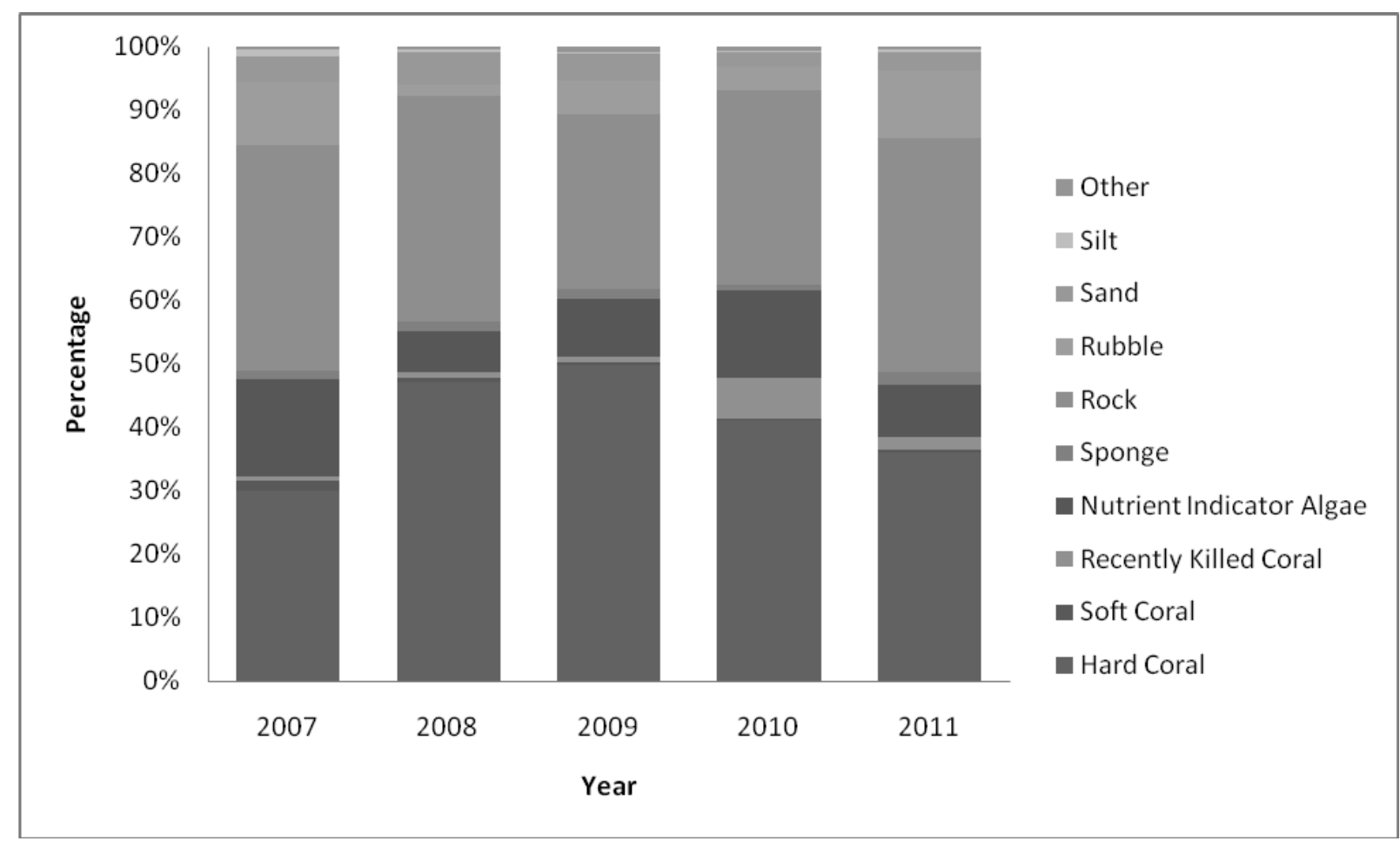

Figure 8. Substrates cover for Perhentian Island from 2007 to 2011

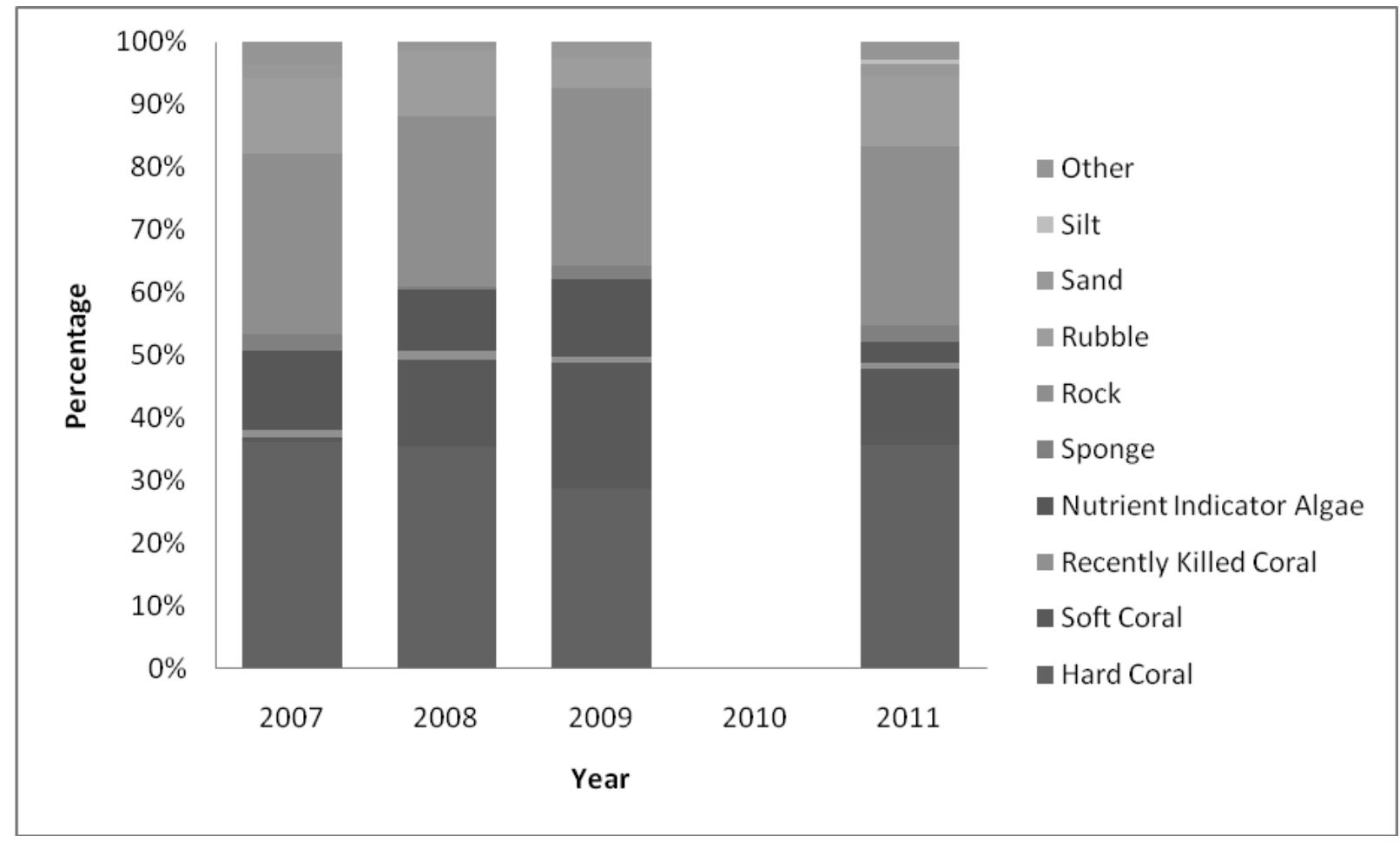

Figure 9. Substrates cover for Redang Island from 2007 to 2011 
aquacultured individuals to build up the populations to the size where they can begin to reproduce naturally may be one option to solving this problem. The average live coral (hard + soft) cover in Tioman and Redang has not changed much over the five years period, whereas the average live coral cover around Perhentian islands has been decreasing since 2009. Greater community involvement in management of these marine protected islands may aid the recovery or coral reefs. Reducing local pressures such as siltation and nutrient enrichment is one of the most obvious steps in building resilience against global threats.

\section{ACKNOWLEDGEMENTS}

Reef Check Malaysia would like to thank all Eco Divers involved in surveys over the past five years as well as dive operators that have supported our work. There are too many to be named but you know who you are.

\section{REFERENCES}

1. Affendi Y. A., Badrul H. T., Lee Y. L., Kee A. A. And Yusri Y. (2005). Scleractinian Coral Diversity of Kg. Tekek, Pulau Tioman Marine Park. Natural Resource Utilisation and Environmental Preservation: Issues and Challenges. Proceedings of Second Regional Symposium on Environment and Natural Resources, Vol 2.

2. Bruno JF and Selig ER (2007) Regional Decline of Coral Cover in the Indo-Pacific: Timing, Extent, and Subregional Comparisons. PLoS ONE 2(8): e711. doi:10.1371/journal.pone.0000711

3. Burke, L., Selig, E., and Spalding, M. (2002). Reefs at risk in South East Asia. World Resources Institute. Washington D.C.

4. Burke, L., Reyter, K., Spalding, M., and Perry, A. (2011). Reefs at Risk Revisited. World Resource Institute. Washington D.C.

5. Cesar, H., Burke, L., and Pet-Soede, L. (2003). The Economics of Worldwide Coral Reef Degradation. Cesar Environmental Economics Consulting (CEEC).

6. Hodgson, G. (1999). A Global Assessment of Human Effects on Coral Reef. Marine Pollution Bulletin 38(5): 345-355. Elsevuer Science Ltd. Great Britain.

7. Hodgson, G., Kiene, W., Mihaly, J., Liebeler, J., Shuman, C., and Maun, L. (2004). Reef Check Instruction Manual: A Guide to Reef Check Coral Reef Monitoring. Reef Check, Institute of the Environment, University of California, Los Angeles.

8. Hodgson, G., Hill, J., Kiene, W., Maun, L., Mihaly, J., Liebeler, J., Shuman, C. and Torres, R. (2006). Reef Check Instruction Manual: A Guide to Reef Check Coral Reef Monitoring. Reef Check Foundation, Pacific Palisades, California, USA.

9. Moberg, F. and Folke, C. (1999). Ecological Goods and Services of Coral Reef Ecosystems. Ecological Economics 29: 215-233.

10. Pilcher, N. and Cabanban, A. (2000). The Status of Coral Reefs in Eastern Malaysia. Report for Global Coral Reef Monitoring Network, Australian Institute of Marine Science, Townsville.

11. Remengesau, T. E. and Michel, J. A. (2004). Foreword. In: Wilkinson, C. (ed). Status of Coral Reefs of the World 2004. Volume 1. Australian Institute of Marine Science, Australia, pp. iii-iv.

12. Stepath, C. M. (2000). Awareness and communitybased monitoring. Proceedings $9^{\text {th }}$ International Coral Reef Symposium Bali, Indonesia 23-27 October 2000, Vol 2.

13. Tebano, T. and Riinga, T. (2002). Some Deep Water Eels of Tarawa Atoll, Kiribati: the Gymnothorax sp. (Muraenidae) and Their Spawning Season. USP Marine Studies Programme. Suva.

14. Tun, K., Chou, L. M., Cabanban, A., Tuan, V. S., Philreefs, Yeemin, T., Suharsono, Sour, K., and Lane, D. (2004). Status of Coral Reefs, Coral Reef Monitoring and Management in Southeast Asia. In: Wilkinson, C. (ed). Status of Coral Reefs of the World 2004. Volume 1. Australian Institute of Marine Science, Australia, pp. 235-275.

15. World Meteorological Organization. (2010). Climate, Carbon and Coral Reefs. WMO-No 1063.

16. Wilkinson, C. (1994). Report of the consultative forum: Third ASEAN-Australia Symposium on Living Coastal Resources of Southeast Asia: Status and Management, Bangkok Thailand, May 1994. Australian Institute of Marine Science. Australia, pp. 7, 37-41. 
Malaysian Journal of Science 32 (SCS Sp Issue) : 117-126 (2013) 